\title{
EVALUASI IMPLEMENTASI SAP MODUL MATERIAL MANAGEMENT: STUDI KASUS PADA PT BUMITAMA GUNAJAYA AGRO
}

\author{
Santo Fernandi Wijaya; Yustina Handoyono \\ Information Systems Department, School of Information Systems, Binus University \\ Jln. K.H. Syahdan No. 9, Palmerah, Jakarta Barat 11480 \\ santofw@binus.ac.id; yuztine_h@yahoo.com
}

\begin{abstract}
An integrated information system is a necessity for a company to help solve problems in business transactions management. SAP application is an application that is able to provide solutions to such problems. The purpose of this study was to evaluate the running business processes on the Material Management module; evaluate the performance of the running SAP systems associated with the implementation and maintenance of SAP applications as well as to give sugestions based on the development of evaluation results obtained, in terms of business processes, performance, and financial. Utilized for analysis is IT Balanced Scorecard method, while ASAP (Accelerated SAP) method is used for the system development. This study produced an analysis of the evaluation of the enterprise business processes in implementing the SAP development of ERP system modules Material Management.
\end{abstract}

Keywords: evaluation, implementation, ERP, SAP, material management module

\begin{abstract}
ABSTRAK
Sistem informasi yang terintegrasi merupakan kebutuhan untuk membantu menyelesaikan permasalahan dalam pengelolaan transaksi bisnis. Aplikasi SAP adalah salah satu aplikasi yang mampu memberikan solusi permasalahan tersebut. Tujuan penulisan penelitian ini adalah untuk mengevaluasi proses bisnis yang berjalan pada modul Material Management, mengevaluasi kinerja sistem SAP berjalan yang berhubungan dengan implementasi dan maintenance aplikasi SAP dan memberikan saran pengembangan berdasarkan hasil evaluasi yang diperoleh, dilihat dari segi PRoses bisnis, kinerja, dan financial. Untuk analisis digunakan metode IT Balanced Scorecard, sementara untuk pengembangan sistem digunakan metodologi ASAP (Accelerated SAP). Penelitian ini menghasilkan analisis tentang evaluasi dari proses bisnis perusahaan dalam melakukan implementasi pengembangan sistem ERP SAP modul Material Management
\end{abstract}

Kata kunci: evaluasi, implementasi, ERP, SAP, modul material management 


\section{PENDAHULUAN}

Penggunaan Sistem Informasi untuk mendukung proses bisnis pada sebuah perusahaan kini telah menjadi suatu tuntutan agar perusahaan dapat mencapai tujuan yang ditetapkan. Oleh karenanya, penerapan Sistem Informasi yang tepat diharapkan menjadi nilai tambah (value added) untuk menjaga agar mata rantai perusahaan tetap berputar dalam menghadapi persaingan secara global dengan menyediakan informasi yang akurat untuk digunakan dalam setiap pengambilan keputusan bisnis. Berangkat dari kondisi dinamika bisnis yang sangat dinamis dan arus informasi yang begitu cepat dan tersebar, maka saat ini perusahaan sangat memerlukan suatu alat yang dapat memproses informasi dengan cepat, tepat dan spesifik yang dapat membantu proses pengambilan keputusan.

Saat ini banyak penyedia sistem Enterprise Resource Planning (ERP) berusaha menawarkan solusi bisnis yang dapat diandalkan sehingga mampu menghasilkan best practice bagi pengguna. Sistem ERP merupakan sistem informasi yang diperuntukkan bagi perusahaan untuk mengintegrasikan dan mengotomatisasikan proses bisnis yang berhubungan dengan aspek operasi, produksi maupun distribusi di perusahaan bersangkutan. Sistem ERP berkembang dari Manufacturing Resource Planning (MRP II) dimana MRP II adalah hasil evolusi dari Material Requirement Planning (MRP) yang berkembang sebelumnya. Sistem ERP secara modular biasanya mengangani proses manufaktur, logistik, distribusi, persediaan (inventory), shiping, pembayaran dan akuntansi perusahaan. Sistem ERP disebut sebagai Back Office System yang mengindikasikan bahwa pelanggan dan masyarakat secara umum tidak dilibatkan dalam sistem ini.

Secara teknis, Sistem ERP berfungsi untuk mengintegrasikan berbagai sistem informasi yang tersebar pada departemen (unit fungsional) suatu Perusahaan. Dengan adanya sistem ERP tersebut, maka unit fungsional terkait dapat saling berbagi informasi yang pada akhirnya dapat meningkatkan sinergi perusahaan. Sistem ERP membantu dalam melakukan standarisasi proses operasi melalui implementasi best practice, sehingga terjadi peningkatan produktivitas, penurunan in-efisiensi, dan peningkatan kualitas produk. Dalam pencapaian standarisasi proses operasi tersebut, terlebih dahulu dilakukan standarisasi data dan informasi melalui keseragaman pelaporan, terutama untuk perusahaan yang memiliki banyak unit bisnis dengan jumlah dan jenis yang berbeda.

Tujuan penulisan penelitian ini ialah untuk mengevaluasi proses bisnis yang berjalan pada PT Bumitama Gunajaya Agro untuk modul Material Management (MM), mengevaluasi kinerja sistem SAP yang berjalan yang berhubungan dengan implementasi dan maintenance aplikasi SAP dan memberikan saran pengembangan berdasarkan hasil evaluasi yang diperoleh, dilihat dari segi proses bisnis, kinerja, dan financial.

Manfaat yang diperoleh dengan implementasi produk ERP, seperti: meningkatkan nilai penjualan, meningkatkan prestige perusahaan, meningkatkan kepercayaan pelanggan, standarisasi proses bisnis untuk mencapai nilai integrasi.

\section{METHOD}

\section{Enterprise Resource Planning (ERP)}

Enterprise Resource Planning (ERP) adalah software lintas fungsi terpadu yang merekayasa ulang proses manufaktur, distribusi, keuangan, sumber daya manusia, dan proses bisnis dasar lainnya dari suatu perusahaan untuk memperbaiki efisiensi, kelincahan, dan profitabilitasnya (O’Brien, 2005, p.699). Sementara menurut Brady et al. (2001, p.153), ERP adalah sebuah sistem yang membantu 
untuk mengatur proses bisnis seperti marketing, produksi, pembelian, dan accounting dalam suatu kesatuan yang terintegrasi. Berdasarkan definisi-definisi tersebut, dapat disimpulkan bahwa ERP merupakan sebuah sistem pendukung proses bisnis guna mengintegrasikan data yang ada untuk menjadikan sebagai informasi yang berguna.

\section{Pengukuran Kinerja}

Menurut Mulyadi (2001, p419), Pengukuran kinerja adalah penentuan secara periodik efektifitas operasional suatu organisasi, bagian organisasi dan karyawan berdasarkan sasaran, standar, dan kriteria yang telah ditetapkan sebelumnya.

Sementara menurut Anderson dan Clancy (Yuwono et al., 2004, p.21) pengukuran kinerja adalah "feed back from the accountant to management that PRovide information about how well the actions rePResent the plans; it also identifies where managers say need to make corrections or adjustments in future planning and controlling activities", atau yang diterjemahkan sebagai "umpan balik dari akuntan kepada manajemen yang memberikan informasi tentang seberapa baik tindakan mewakili rencana, selain itu juga mengidentifikasi kapan manajer perlu mengatakan untuk melakukan koreksi atau penyesuaian dalam perencanaan masa depan dan mengendalikan kegiatan'.

Dari definisi-definisi tersebut di atas, dapat disimpulkan bahwa pengukuran kinerja adalah tindakan pengukuran yang dilakukan terhadap berbagai aktivitas dalam rantai nilai yang ada pada perusahaan. Hasil pengukuran tersebut kemudian digunakan sebagai umpan balik yang akan memberikan informasi tentang prestasi pelaksanaan suatu rencana dan titik dimana perusahaan memerlukan penyesuaian-penyesuaian atas aktivitas perencanaan dan pengendalian.

Menurut Lynch dan Cross (Yuwono et al., 2004, p.29) manfaat pengukuran kinerja yang baik adalah sebagai berikut: (1) menelusuri kinerja terhadap harapan pelanggan sehingga akan membawa perusahaan lebih dekat dengan pelanggannya dan membuat seluruh orang dalam organisasi terlibat dalam upaya memberi kepuasan kepada pelanggannya; (2) memotivasi pegawai untuk melakukan pelayanan sebagai bagian dari mata rantai pelanggan dan pemasok internal; (3) mengidentifikasi berbagai pemborosan sekaligus mendorong upaya-upaya pengurangan terhadap pemborosan tersebut (reduction of wastes); (4) membuat suatu tujuan strategis yang biasanya masih kabur menjadi lebih konkret sehingga mempercepat proses pembelajaran organisasi; (5) membangun konsensus untuk melakukan suatu perubahan dengan memberi reward atas perilaku yang diharapkan tersebut.

\section{SAP}

SAP berasal dari Jerman yang diperkenalkan pada tahun 1972 berarti systeme, anwendungen and PRodukte in derdatenverarbeitung. Dalam bahasa Inggris adalah systems, applications, and products in data processing. SAP merupakan vendor utama software ERP di Mannheim, Jerman yang dibangun oleh lima orang dari IBM (Brady et al., 2001, p.21).

Produk-produk SAP antara lain: (1) MySAP business suite, yaitu paket lengkap dari open enterprise solution yang menghubungkan semua orang yang dilibatkan, informasi dan proses dan oleh karena itu meningkatkan efektifitas dari hubungan bisnis. MySAP business suite menawarkan solusi bisnis yang fleksibel untuk perusahaan yang besar yang mempunyai jumlah user yang besar dan proses yang secara konstan berubah; (2) MySAP all-in-one, yaitu prepackaged, versi spesifikasi industri dari MySAP Business Suite dengan built-in content, peralatan, dan metodologi untuk biaya yang efektif. Solusi mySAP all-in-one menawarkan kombinasi fleksibel out-of-the- box dengan kekuatan dari SAP solusi bisnis kelas dunia; (3) SAP business one, yaitu sesuatu yang mudah digunakan untuk bisnis dan solusi untuk manajemen operasional untuk bisnis dinamik dengan ukuran karyawan antara sepuluh 
sampai beberapa ribu. Solusi ini mudah namun sangat kuat, menyediakan dengan segera dan melengkapi gambaran operasi bisnis dan aktifitas pelanggan.

Modul-modul pada SAP antara lain: (1) modul Sales and Distribution (SD) - menyimpan sales order dan jadwal pengiriman. Informasi mengenai pelanggan (harga, bagaimana dan dimana pengiriman produk, bagaimana pelanggan membayar dan informasi lainnya) dikelola dan diakses dari modul ini; (2) modul Material Management (MM) - mengatur akuisisi bahan baku dari supplier dan kemudian penanganan penyimpanan bahan baku, dari gudang untuk diproses sampai penyimpanan barang jadi; (3) modul production Planning (PP) - memelihara informasi produksi. Disini produksi direncanakan dan dijadwalkan, dan aktifitas produksi disimpan; (4) modul Quality Management (QM) - membantu untuk merencanakan dan menyimpan aktifitas control kualitas, seperti pemeriksaan produk dan keterangan material; (5) modul Plant Maintenance (PM) - memungkinkan perencanaan untuk pencegahan perawatan mesin-mesin pabrik dan mengatur perawatan sumber daya, jadi kerusakan perlengkapan dapat diminimalisasi; (6) modul Human Resource (HR) - memfasilitasi perekrutan karyawan, hiring, dan pelatihan. Modul ini dilengkapi penggajian dan benefit; (7) modul Financial Accounting (FI) - menyimpan transaksi dalam catatan buku besar. Juga menghasilkan pernyataan untuk kegunaan laporan eksternal; (8) modul Controlling (CO) - untuk manajemen internal. Disini, biaya pabrik perusahaan ditempatkan pada produk dan cost center, memfasilitasi analisis biaya; (9) modul Asset Management (AM) - membantu perusahaan untuk mengatur pembelian asset tetap (pabrik dan mesin) dan hubungan depresiasi; (10) modul Project System (PS) memungkinkan perencanaan dan mengontrol kelebihan $R \& D$, konstruksi, dan proyek pemasaran. Modul ini memungkinkan agar biaya dikumpulkan pada proyek, dan ini sering digunakan untuk mengatur implementasi dari sistem SAP R/3; (11) modul Workflow (WF) - untuk mengotomatisasi beberapa aktifitas dalam R/3. Modul ini dapat menampilkan analisis alur tugas dan mendorong karyawan (via email) jika mereka membutuhkan untuk menerima aksi; (12) modul Industry Solutions (IS) - pengaturan konfigurasi R/3 yang ada di SAP adalah tepat untuk fakta-fakta industri. Pengaturan ini mempermudah implementasi $\mathrm{R} / 3$ dan membiarkan pembeli mendapat keuntungan dari pengalaman industri SAP.

\section{SAP Business All-in-One}

SAP Business all-in-one menyediakan solusi yang terintegrasi dan komprehensif yang dikombinasikan dengan best practice dalam meningkatkan penjualan, keuangan dan proses operasional dalam proses bisnis. Implementasi SAP Business all-in-one dapat meningkatkan standar prosedur, kontrol, dan best practice lintas perusahaan, memperkuat akuntabilitas dan alignment perusahaan. Data dapat dikonsolidasikan dari banyak aplikasi ke dalam sebuah solusi terintegrasi. SAP Business all-in-one menawarkan solusi flexibilitas out-of-the-box yang dikombinasikan dengan kekuatan dari solusi bisnis SAP (SAP AG, 2006).

Keuntungan bisnis yang bisa diperoleh dari SAP Business all-in-one ini mencakup: (1) tingkat implementasi dan transparansi biaya yang tinggi - SAP Business all-in-one tersedia atas kerjasama dari partner yang berkualifikasi dan terpercaya, familiar dengan tantangan segmen pasar dan industri. Diimplementasikan menggunakan metode implementasi khusus yang didasarkan pada pengalaman yang telah diperoleh dari instalasi di lebih dari 20 area industri di seluruh dunia. Dibandingkan dengan sistem tradisional, perusahaan mampu menghemat biaya hingga $40 \%$ dan mengurangi waktu implementasi hingga 30\%; (2) meningkatkan produktivitas dan pengendalian biaya - SAP Business all-in-one mampu mengintegrasikan segi finansial, sumber daya manusia, logistik, dan hubungan dengan pelanggan. Dengan demikian perusahaan mampu memperoleh keuntungan dari segi pelanggan atas meningkatnya transparansi dan proses administrasi yang mudah; (3) partner yang terpercaya partner SAP menawarkan solusi komprehensif yang terdiri dari perangkat keras (hardware), perangkat lunak (software), dan konsultasi yang telah dirancang untuk kebutuhan bisnis skala kecil hingga menengah; (4) skalabilitas - SAP Business all-in-one dapat dengan mudah diadaptasi bagi perubahan kebutuhan bisnis (business requirement). 


\section{Material Management}

Menurut Business Dictionary.com, PRocurement atau pengadaan barang adalah:

The process of obtaining goods and services from preparation and processing of a requisition through to receipt and approval of the invoice for payment. It commonly involves (1) purchase planning, (2) standards determination, (3) specifications development, (4) supplier research and selection, (5) value analysis, (6) financing, (7) price negotiation, (8) making the purchase, (9) supply contract administration, (10) inventory control and stores, and (11) disposals and other related functions.

'Proses untuk mendapatkan barang dan jasa dari persiapan dan pengolahan daftar permintaan melalui penerimaan dan persetujuan dari faktur pembayaran, yang biasanya melibatkan (1) perencanaan pembelian, (2) penentuan standar, (3) pengembangan spesifikasi, (4) penelitian dan pemilihan pemasok, (5) analisis nilai, (6) pembiayaan, (7) negosiasi harga, (8) pembelian, (9) administrasi kontrak pasokan, (10) kontrol persediaan dan toko, dan (11) pelepasan dan fungsi terkait lainnya.'

Singkatnya, pengadaan barang adalah proses lengkap untuk mendapatkan barang dan jasa dari persiapan dan proses permintaan melalui bukti dan persetujuan kwitansi dari pembayaran”.

Berdasarkan Wikipedia, “Material Management merupakan salah satu modul logistik yang menangani komponen tangible dari supply chain, membantu manajemen dalam perolehan produk jadi maupun bahan baku, pengontrolan kualitas dari proses pembelian dan pemesanan, serta standar yang berlaku dalam proses pemesanan, pengiriman dan persediaan barang”.

Proses pengadaan barang dalam modul Material Management yaitu: (1) permintaan pembelian barang; (2) penentuan vendor; (3) penyeleksian vendor; (4) proses pemesanan dan pembuatan Purchase Order; (5) penerimaan barang; (6) verifikasi tagihan; (7) proses pembayaran.

\section{Balanced Scorecard}

Menurut Kaplan dan Norton (Yuwono et al., 2004, p.7), balanced scorecard adalah seperangkat pengukuran yang memberikan pandangan bisnis yang cepat dan komprehensif bagi manager puncak, termasuk pengukuran keuangan yang menjelaskan hasil dari kejadian yang telah terjadi, pengukuran keuangan tersebut dilengkapi dengan pengukuran operasional pada kepuasan pelanggan, proses bisnis internal, inovasi organisasi dan perbaikan aktivitas operasional yang mengarah pada kinerja keuangan di masa depan.

Menurut Tunggal (2002, p.1), balanced scorecard adalah kumpulan ukuran kinerja yang terintegrasi yang diturunkan dari strategi perusahaan yang mendukung strategi perusahaan secara keseluruhan.

Sementara Anthony, Banker, Kaplan, dan Young (Yuwono et al., 2004, p.8) mendefinisikan balanced scorecard sebagai suatu pengukuran dan sistem manajemen yang menampilkan hasil unitunit bisnis dari empat perspektif yaitu keuangan, pelanggan, proses bisnis internal, serta pembelajaran dan pertumbuhan.

Dengan demikian dapat disimpulkan bahwa balanced scorecard merupakan suatu pengukuran kinerja yang cepat, tepat dan komprehensif yang memberikan pandangan dan pemahaman bagi manajer tentang performa bisnis yang ada. Pengukuran kinerja tersebut dilihat dari empat perspektif, yaitu perspektif keuangan, perspektif pelanggan, perspektif proses bisnis internal, dan perspektif pembelajaran dan pertumbuhan (Gambar 1). 


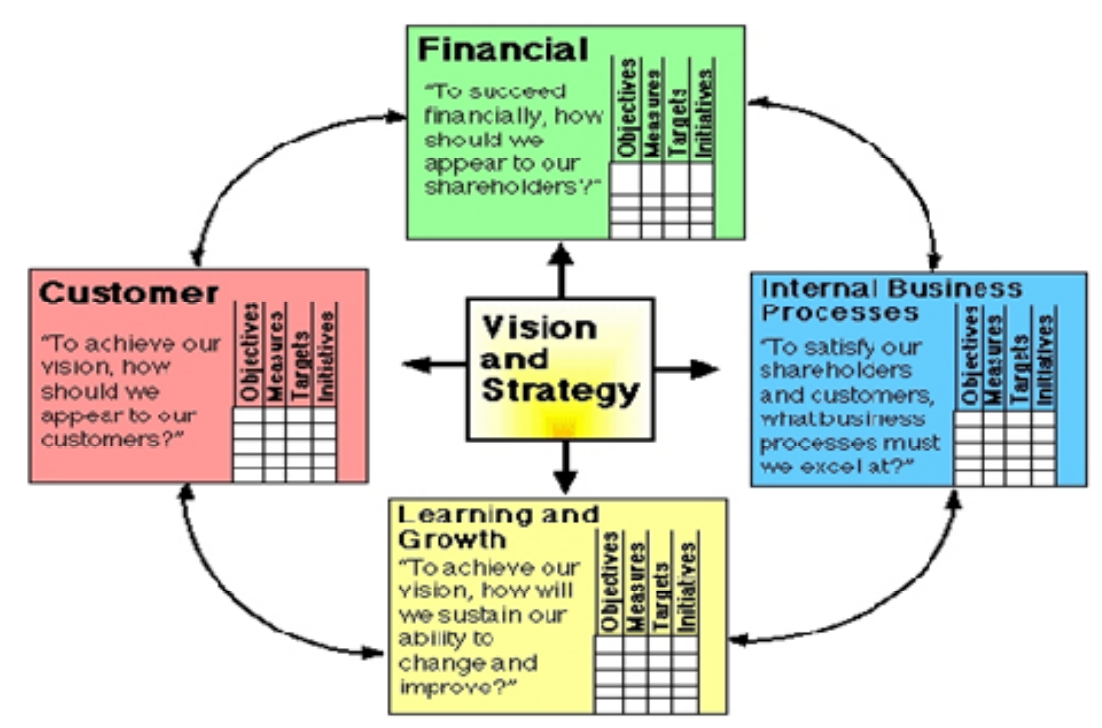

Gambar 1. Balanced scorecard sebagai suatu sistem manajemen kinerja.

\section{IT Balanced Scorecard}

Konsep IT Balanced Scorecard pertama kali dikembangkan oleh Wim Van Grembergen (2000) pada tahun 1997 sebagai pengembangan Balanced Scorecard. Pendekatan IT Balanced Scorecard hadir ketika minat terhadap teknologi informasi (TI) meningkat sehingga muncul masalah tentang bagaimana mengevaluasi fungsi teknologi informasi perusahaan. IT Balanced Scorecard memberikan gambaran kinerja keseluruhan unit TI berdasarkan visi, misi dan strategi TI perusahaan. Grembergen (2000) membagi IT Balanced Scorecard menjadi empat perspektif yaitu perspektif yaitu perspektif kontribusi perusahaan, perspektif orientasi pengguna, perspektif penyempurnaan operasional, dan perspektif orientasi masa depan.

\section{HASIL DAN PEMBAHASAN}

\section{Sistem Informasi Pembelian dan Proses Bisnis PT Bumitama Gunajaya Agro}

Sistem informasi Pembelian (Gambar 2) diterapkan oleh departemen Purchasing dan Departemen Logistik. Sistem informasi ini berguna untuk menangani proses pembelian, perencanaan pengadaan barang, serta memantau stok yang tersedia di gudang. Sistem informasi pembelian PT Bumitama Gunajaya Agro menggunakan modul Material Management di SAP Business All in One yang sudah terintegrasi dengan sistem-sistem lainnya (Gambar 3).

\section{Purchase Requisition (PR)}

Purchase Requisition (PR) merupakan dokumen yang dibuat oleh staff departemen untuk kantor pusat dan Bagian Gudang untuk unit kerja yang berguna untuk meminta pembelian barang (Gambar 4). PR (Purchase Requisition) harus disetujui oleh kepala wilayah untuk unit kerja, kepala departemen masing-masing untuk kantor pusat dan atau direksi. Setelah PR (Purchase Requisition) disetujui, status PR akan menjadi Fully release. Setelah status PR menjadi Fully Release maka PR akan di proses lebih lanjut oleh Departemen Purchasing untuk proses selanjutnya. PR dibuat 2 bulan sebelum barang dibutuhkan untuk kantor pusat, hal ini dimaksudkan agar jika PR mengalami 
keterlambatan dalam proses persetujuan. Untuk barang-barang untuk proses produksi akan dipesan setiap bulan. Jumlah barang yang akan dipesan untuk keperluan produksi didapat dari modul Production Plan.

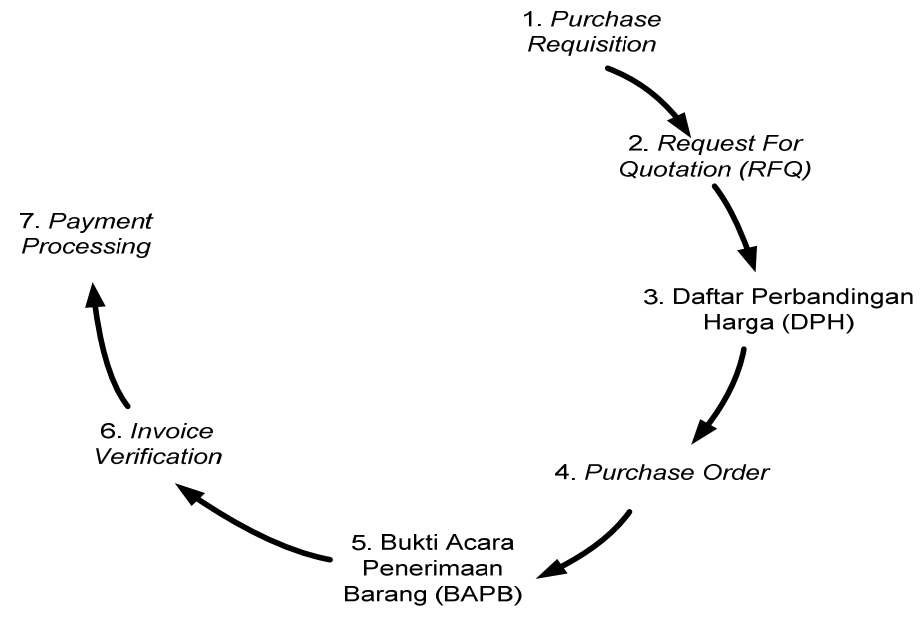

Gambar 2. Flow procurement system.

\section{Request for Quotation (RFQ)}

RFQ (Gambar 5) merupakan dokumen yang dibuat pada saat Departemen Purchasing menerima PR yang sudah berstatus Fully Release. Bagian Purchasing akan mengirimkan RFQ ke vendor. Dokumen RFQ ini digunakan untuk meminta harga yang ditawarkan oleh vendor untuk item yang ada di dalam dokumen PR. RFQ (Request for Quotation) akan berisi daftar barang yang akan dibeli, jumlah barang serta spesifikasi barang yang sesuai dengan PR. Untuk saat ini data vendor akan di-input oleh departemen IT.

\section{Quotation}

Quotation merupakan dokumen balasan dari vendor. Balasan ini biasanya berisi harga barangbarang yang diminta pada RFQ. Setelah Quotation diterima oleh Departemen Purchasing, Quotation akan dijadikan panduan untuk pembuatan DPH (Daftar Perbandingan Harga).

\section{Daftar Perbandingan Harga (DPH)}

Setelah menerima quotation-quotation dari vendor, sistem akan membandingkan quotation dengan quotation yang lainnya. Setelah proses perbandingan selesai, akan didapat satu penawaran yang terbaik baik dari segi harga maupun kualitas vendor. Dokumen DPH (Gambar 6) ini akan disetujui oleh Owner. Untuk saat ini Owner yang memiliki tanggung jawab untuk menganalisis DPH dan menentukan vendor yang akan dipakai. Setelah disetujui oleh Owner, DPH akan diberikan kembali kepada Departemen Purchasing untuk proses selanjutnya.

\section{Purchase Order (PO)}

Setelah DPH disetujui oleh owner, akan didapat vendor. Kemudian, Departemen Purchasing akan membuat PO (Gambar 7) yang berisi nama barang, jumlah barang serta harga barang. Proses release $\mathrm{PO}$ /persetujuan $\mathrm{PO}$ harus melihat nilai $\mathrm{PO}$ tersebut terlebih dahulu. 


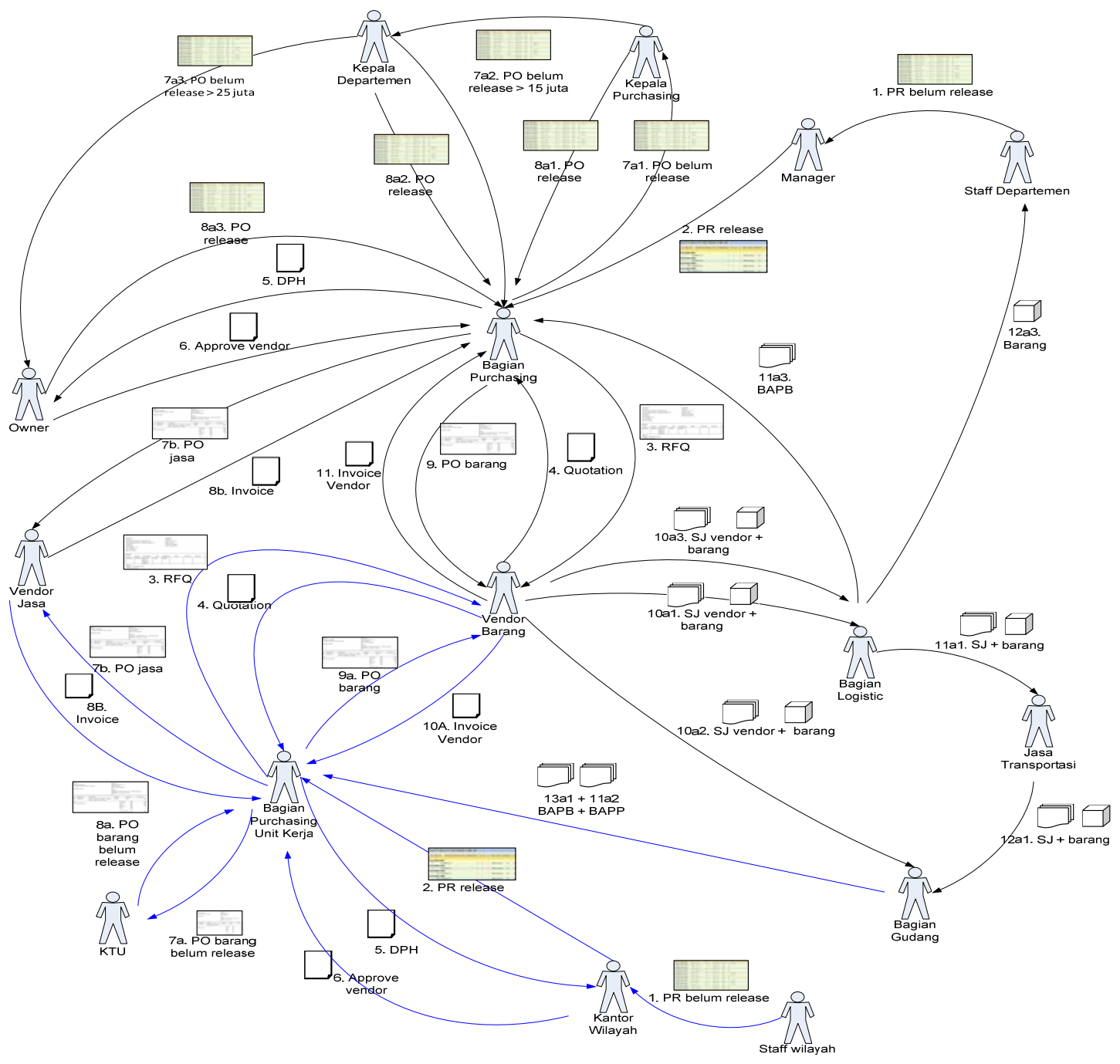

Gambar 3. Rich picture PRocurement cycle.

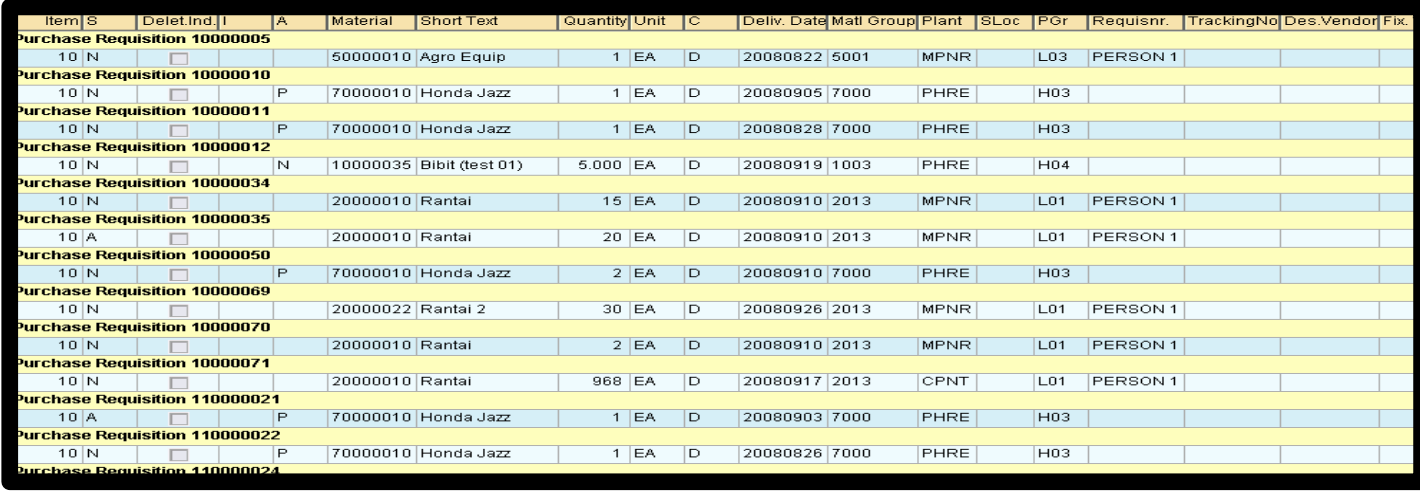

Gambar 4. Tampilan Purchase Requisition. 
AGROTANI UNGGUL LESTAR, PT

JL.LAPANGAN BOLA, KEBUN JERUK 10

JAKARTA

JAKARTA

$021-53668219$

081311114071

Material

\begin{tabular}{|c|c|l|l|l|l|l|l|}
\hline No & PR No & Description & \multicolumn{1}{c|}{ Qty } & Destination & Merk & Unit Price & Remarks \\
\hline 60000044 & 110000139 & $\begin{array}{l}\text { Plate MS } \\
\text { Smm Uk. } \\
\end{array}$ & & S LMB & PNBM \\
& & & & & & \\
& & & & & & \\
\hline
\end{tabular}

Ship To:

Manggis V KPR-BTN Blok J

(*) Coret salah satu

Gambar 5. Tampilan Request for Quotation.

Price Comparison List in Currency IDR

\begin{tabular}{|c|c|c|c|c|c|c|c|c|c|}
\hline 14 & $\mathbf{V}$ & \multicolumn{2}{|c|}{ Quotaticn } & Gis & Material & 6 & Vendor & Additional Info & 졸 \\
\hline $\begin{array}{l}\text { Material } \\
\text { Sh. Text } \\
\text { oty. in Bas }\end{array}$ & e Unit & & $\begin{array}{l}\text { Quo } \\
\text { Bid } \\
\text { Nam }\end{array}$ & $\begin{array}{l}\text { : : } \\
\text { ler: } \\
:\end{array}$ & $\begin{array}{l}60 \\
20 \\
M a\end{array}$ & $\begin{array}{l}\text { EQGe } \\
\text { EQOE } \\
\text { ju T }\end{array}$ & Terus & $\begin{array}{l}60003000 \\
100011 \\
\text { Tejo }\end{array}$ & \\
\hline $\begin{array}{l}20000010 \\
\text { Rantai }\end{array}$ & 10 & $\mathrm{EA}$ & $\begin{array}{l}\text { Va7 } \\
\text { Pri } \\
\text { Ran }\end{array}$ & & & 1 & $\begin{array}{rr}\text { 1. } 000 & 000 \\
100 & 000 \\
9 & 8\end{array}$ & 2 & $\begin{array}{l}200 \cdot 000 \\
120.000 \\
199 \approx\end{array}$ \\
\hline $\begin{array}{l}20000013 \\
\text { Snarp nart }\end{array}$ & 2 & EA & $\begin{array}{l}\text { Vat } \\
\text { Pri } \\
\text { Ran }\end{array}$ & & & 1 & 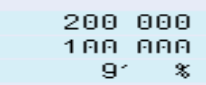 & 2 & 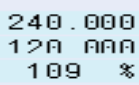 \\
\hline Total Quot. & & & $\begin{array}{l}\text { Val } \\
\text { Ran }\end{array}$ & & & 1 & $\begin{array}{c}200 \\
9\end{array}$ & 2 & $\begin{array}{c}440.000 \\
109\end{array}$ \\
\hline
\end{tabular}

Gambar 6.Tampilan daftar perbandingan harga.

Proses penyetujuan Purchase Requisition (PR) terdapat tiga tingkatan: (1) tingkat rendah jika nilai PO kurang dari Rp.5 juta, dapat langsung diproses dengan catatan sudah mendapat persetujuan dari Manager atau dapat langsung diproses pada tingkat daerah; (2) tingkat sedang - jika nilai PO antara Rp.5-25 juta harus dapat mendapat persetujuan dari kepala departemen yang terkait dan Kepala Departemen Purchasing; (3) tingkat tinggi - jika nilai PO di atas Rp.25 juta, baru dapat dikatakan mendapat persetujuan penuh setelah mendapat persetujuan dari tiga departemen (kepala Departemen purchasing, kepala departemen terkait, dan direksi).

\section{Invoice Vendor}

Invoice vendor merupakan dokumen vendor yang berisi tagihan yang jumlahnya sesuai dengan nilai PO. Invoice vendor akan diterima oleh Departemen Purchasing dan barang yang dikirimkan oleh vendor akan langsung diterima oleh Departemen Logistik. Invoice vendor ini akan dipakai untuk proses invoice verification.

\section{Berita Acara Penerimaan Barang (BAPB)}

BAPB (Gambar 8) merupakan dokumen yang dibuat setelah Departemen Logistik (untuk kantor pusat) atau Departemen Gudang (untuk unit kerja) menerima barang yang dikirim oleh vendor. 
Setelah itu Departemen Logistik akan mengirim BAPB ke Departemen Purchasing. Dokumen BAPB ini akan digunakan oleh Departemen Purchasing pada saat Invoice Verification. Setelah barang diterima oleh Departemen Logistik di kantor pusat, Departemen Logistik akan langsung menyerahkan barang tersebut ke departemen yang meminta (departemen yang membuat PR). Pada saat penyerahan barang berlangsung tidak ada sebuah dokumen yang menandakan bahwa barang tersebut telah benar diberikan kepada departemen yang meminta dengan jumlah dan item barang yang sesuai. Saat ini hal tersebut tidak bermasalah tapi tidak menutup kemungkinan akan terjadi kesalahpahaman/kecurangan.

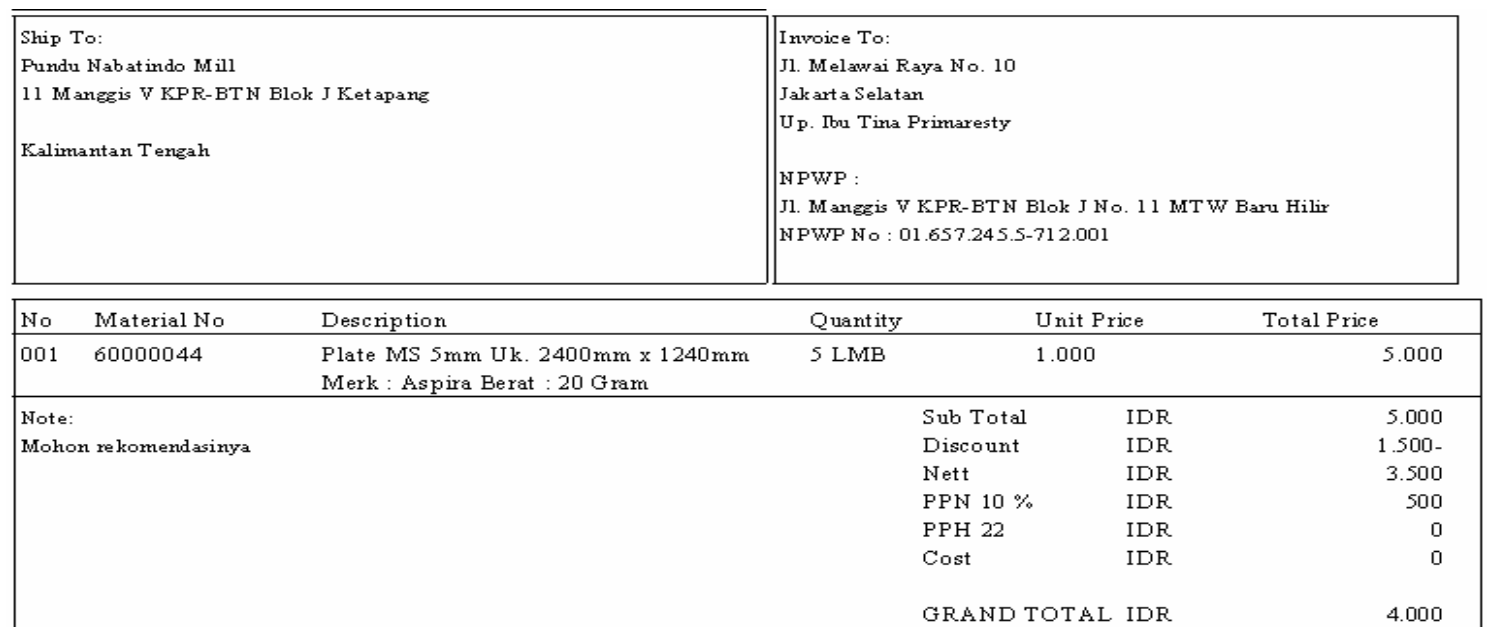

Gambar 7. Tampilan PO (Purchase Order).

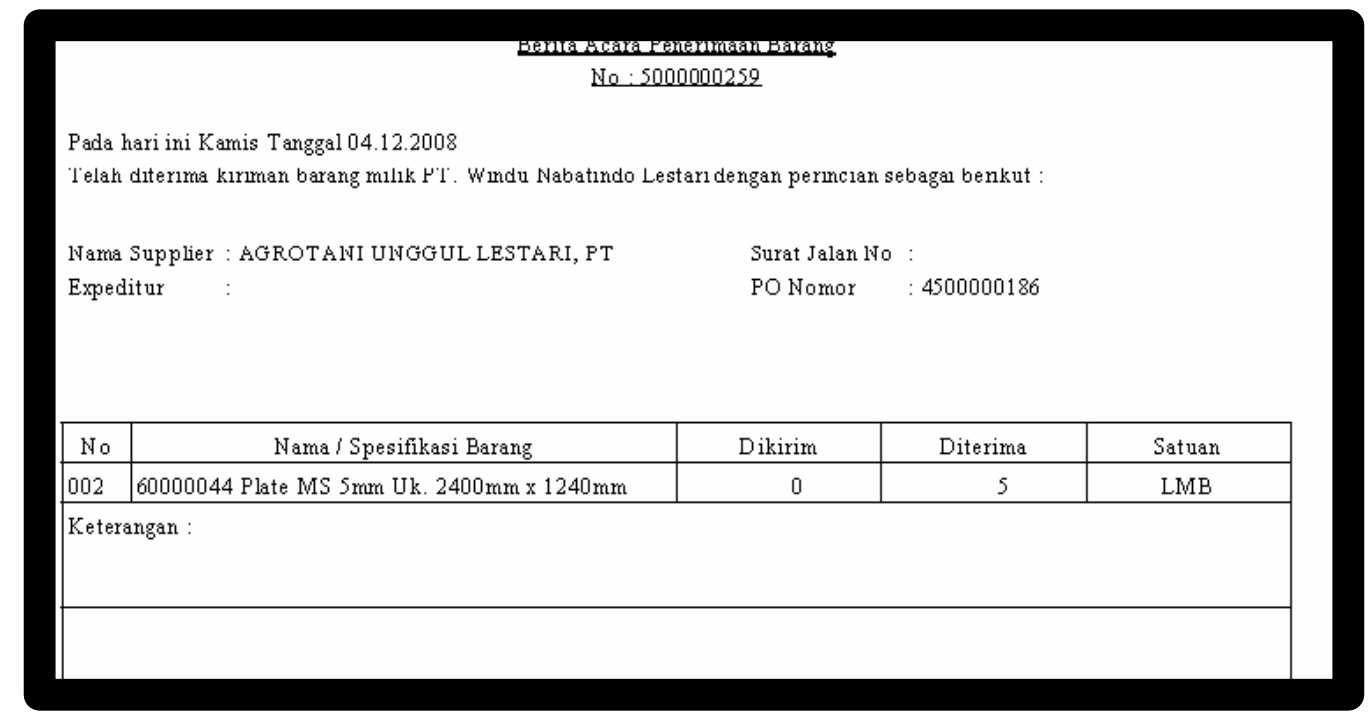

Gambar 8. Tampilan BAPB.

\section{Berita Acara Penyerahan Pekerjaan (BAPP)}

BAPP (Gambar 9) merupakan dokumen yang dibuat ketika perusahaan menerima jasa dari vendor jasa. Dokumen ini menandakan bahwa jasa telah selesai dilakukan oleh vendor jasa. BAPP dibuat oleh Bagian Gudang untuk unit kerja pada saat Bagian Gudang menerima barang dari jasa transportasi. Dokumen ini akan diserahkan ke Departemen Purchasing unit kerja yang akan dipakai untuk pembayaran jasa kepasa vendor jasa. 


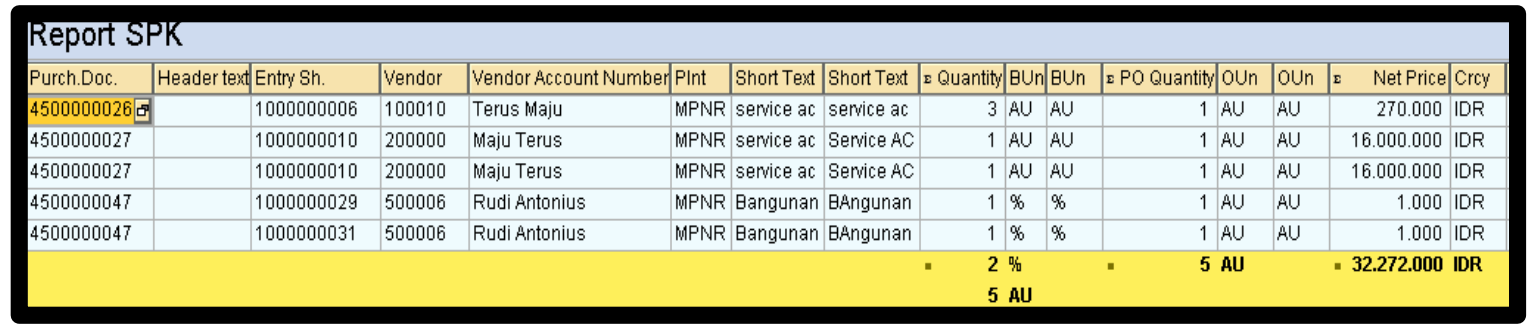

Gambar 9. Tampilan BAPP.

\section{Invoice Verification}

Invoice Verification (Gambar 10) dilakukan oleh Departemen Purchasing. Dalam Invoice Verivication, Departemen Purchasing akan mengecek invoice vendor, BAPB (berita acara penerimaan barang), dan BAPP (berita acara penyerahan pekerjaan). Invoice Verivication dilakukan agar pembayaran kepada vendor barang maupun vendor jasa tidak mengalami kesalahan.

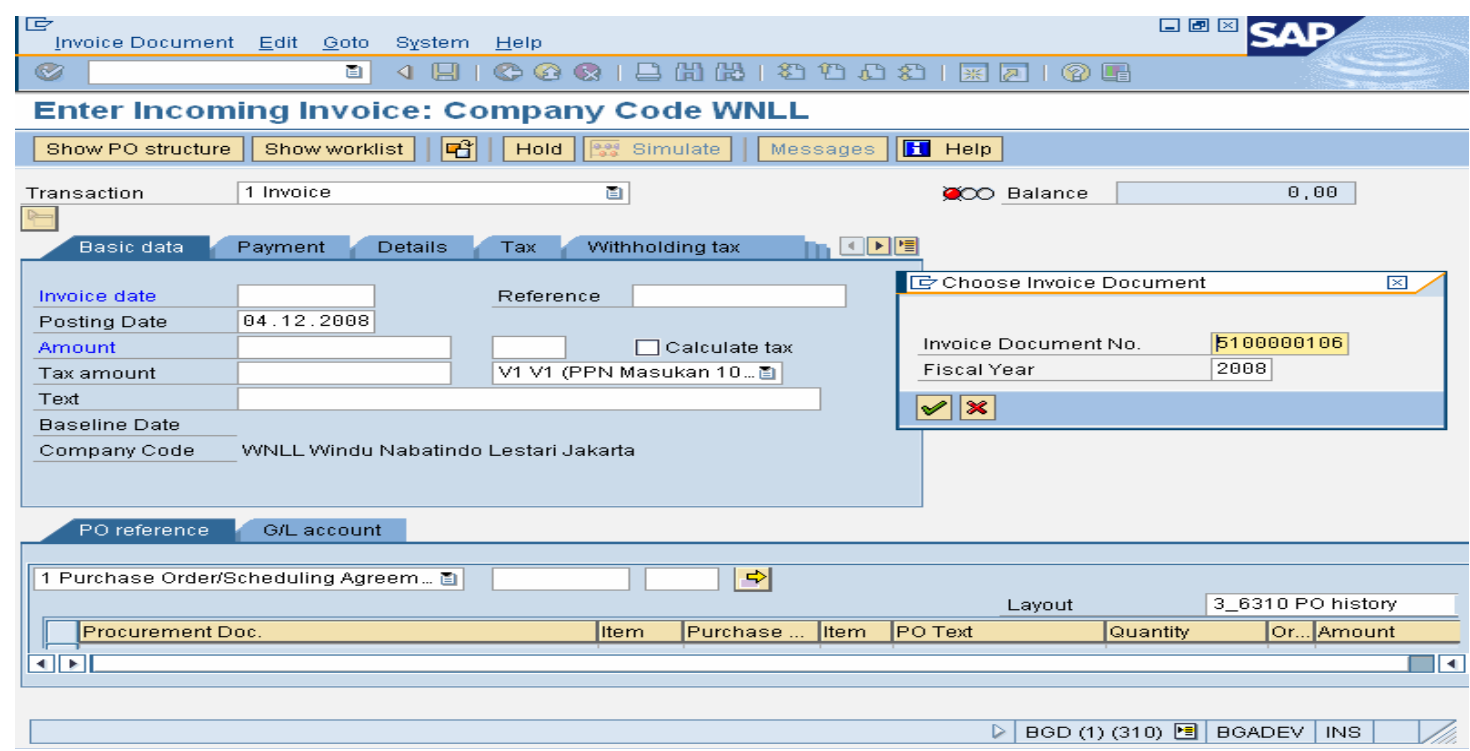

Gambar 10. Tampilan UI pembuatan invoice.

\section{Evaluasi Hasil Pengukuran Kinerja Sistem}

Secara lebih ringkas hasil pengukuran kinerja sistem dapat dilihat pada Tabel 1 dan Gambar 11 berikut ini:

Tabel 1

Ringkasan Hasil Pengukuran Kinerja Divisi IT

\begin{tabular}{lrr}
\hline \multicolumn{1}{c}{ Perspektif } & Sasaran Strategis & Hasil Pengukuran \\
\hline Kontribusi Perusahaan & $80 \%$ & $96 \%$ \\
Orientasi Pengguna & $70 \%$ & $53,5 \%$ \\
Keunggulan Operasional & $70 \%$ & $75 \%$ \\
Orientasi Masa Depan & $80 \%$ & $80 \%$ \\
\hline Rata - rata & & $\mathbf{7 6 , 1 2 \%}$ \\
\hline
\end{tabular}




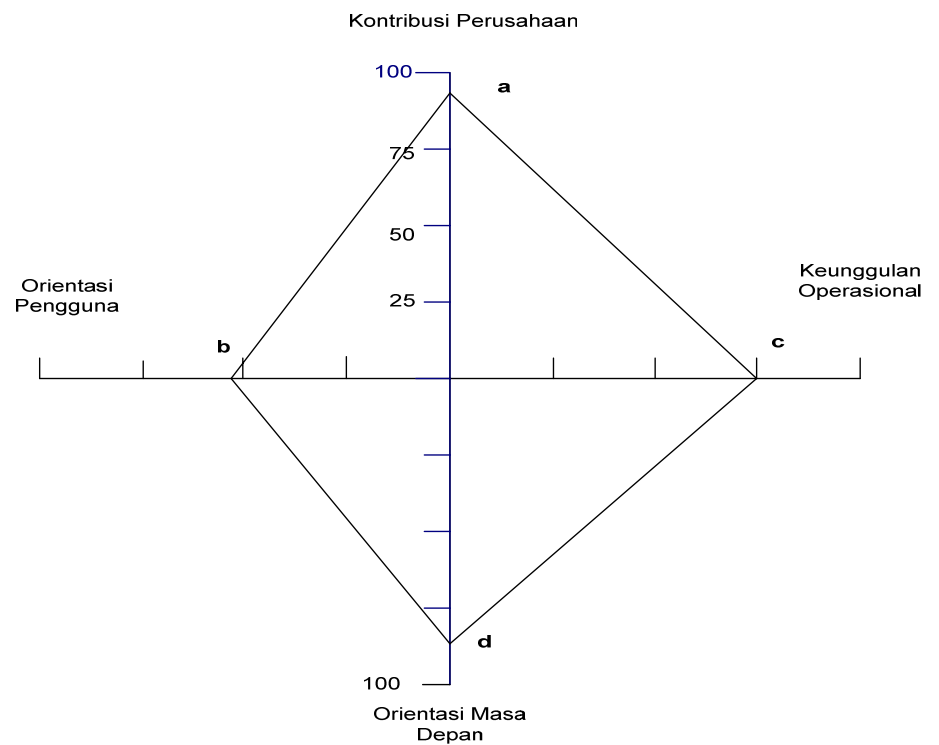

Gambar 11. Grafik hasil pengukuran kinerja divisi IT.

Setelah dilakukan pengukuran melalui perspektif IT Balanced Scorecard, dapat dilakukan evaluasi hasil pengukuran terhadap hasil rata-rata pencapaian yang diperoleh oleh masing-masing perspektif. Dari keempat perspektif di atas, melalui konsultasi dan pertimbangan dari PT Bumitama Gunajaya Agro, dapat dibuat empat kategori bobot/nilai range persentase sebagai berikut:

$0 \%-25 \%$ : warning

26\% - 50\%: challenged

$26 \%-75 \%$ : good

$76 \%$ - 100\%: very good

Atas dasar range tersebut, yaitu dari hasil pengukuran keempat perspektif tadi, sistem SAP Business All-in-One versi 7.10 di PT Bumitama Gunajaya Agro saat ini termasuk dalam kategori very good dengan rata-rata $76,12 \%$.

\section{Analisis Kesesuaian Proses Bisnis}

Tabel 2 di bawah ini memuat hasil analisis kesesuaian proses bisnis.

Tabel 2

Analisis Kesesuaian Proses Bisnis

\begin{tabular}{|c|c|c|c|c|c|}
\hline No & Requirement & Rank & Current & Comments & Alternatives \\
\hline 1. & $\begin{array}{l}\text { Proses permintaan pembelian } \\
\text { (purchase requisition): } \\
\text { Informasi yang lengkap dan } \\
\text { jelas }\end{array}$ & $\mathrm{H}$ & $\mathrm{F}$ & $\begin{array}{l}\text { Terjadi perubahan bentuk } \\
\text { pemrosesan PR dari } \\
\text { hardcopy menjadi by sistem }\end{array}$ & \\
\hline 2. & $\begin{array}{l}\text { Proses release PR: } \\
\text { Yang tepat waktu dan tepat } \\
\text { sasaran }\end{array}$ & $\overline{\mathrm{H}}$ & $\mathrm{G}$ & $\begin{array}{l}\text { Proses release PR masih } \\
\text { banyak terjadi } \\
\text { keterlambatan. }\end{array}$ & $\begin{array}{l}\text { Membuat sebuah } \\
\text { list reminder untuk } \\
\text { release PR }\end{array}$ \\
\hline 3. & $\begin{array}{l}\text { Proses evaluasi vendor lama: } \\
\text { Dapat menilai kinerja vendor } \\
\text { dengan akurat secara objektif } \\
\text { tidak secara subjektif }\end{array}$ & $\mathrm{M}$ & G & $\begin{array}{l}\text { Perusahaan belum } \\
\text { menerapkan dan } \\
\text { menjalankan sistem evaluasi } \\
\text { kelayakan bagi vendor lama }\end{array}$ & $\begin{array}{l}\text { Menggunakan fitur } \\
\text { evaluasi vendor } \\
\text { yang sudah } \\
\text { tersedia di SAP }\end{array}$ \\
\hline
\end{tabular}




\begin{tabular}{|c|c|c|c|c|c|}
\hline 4. & $\begin{array}{l}\text { Proses penawaran dan } \\
\text { perbandingan harga dari } \\
\text { vendor (RFQ dan Price } \\
\text { Comparison): } \\
\text { Dapat melakukan } \\
\text { perbandingan harga secara } \\
\text { spesifik sehingga membantu } \\
\text { mempermudah pengambilan } \\
\text { keputusan }\end{array}$ & $\mathrm{L}$ & $\mathrm{P}$ & $\begin{array}{l}\text { Format perbandingan harga } \\
\text { dan vendor kurang detil }\end{array}$ & \\
\hline 5. & $\begin{array}{l}\text { Proses release dan persetujuan } \\
\text { PO: } \\
\text { Waktu yang singkat tanpa } \\
\text { harus tertunda karena faktor } \\
\text { human error }\end{array}$ & $\mathrm{H}$ & $\mathrm{G}$ & $\begin{array}{l}\text { Proses persetujuan PO masih } \\
\text { banyak terjadi keterlambatan } \\
\text { karena change habit belum } \\
\text { berjalan. }\end{array}$ & $\begin{array}{l}\text { Membuat sebuah } \\
\text { aplikasi reminder } \\
\text { melalui email }\end{array}$ \\
\hline 6 & $\begin{array}{l}\text { Proses pembelian (Purchase } \\
\text { Order): Informasi pembelian } \\
\text { yang lengkap dan terintegrasi. } \\
\text { Pemisahan nomor PO antara } \\
\text { satu perusahaan dengan } \\
\text { perusahaan lainnya agar dapat } \\
\text { menghasilkan laporan yang } \\
\text { baik serta tepat sesuai dengan } \\
\text { kebutuhan } \\
\text { adanya pencatatan untuk jasa } \\
\text { transportasi }\end{array}$ & $\mathrm{H}$ & $\mathrm{P}$ & $\begin{array}{l}\text { Kondisi saat ini, pada saat } \\
\text { membuat PO harus meng- } \\
\text { entry kembali nomor } \\
\text { reference document, yaitu } \\
\text { nomor PR. } \\
\text { Tidak ada pemisahan nomor } \\
\text { PO yang } \\
\text { mengidentifikasikan asal PO } \\
\text { tersebut dibuat. }\end{array}$ & $\begin{array}{l}\text { Melakukan } \\
\text { kustomisasi pada } \\
\text { program } \\
\text { Membuat PO } \\
\text { khusus untuk } \\
\text { pencatatan jasa } \\
\text { transportasi. }\end{array}$ \\
\hline 7 & $\begin{array}{l}\text { Proses pencatatan penerimaan } \\
\text { (good receipt): } \\
\text { Pencatatan harus sesuai dengan } \\
\text { jumlah barang diterima dan } \\
\text { tidak terjadi kesalahan dalam } \\
\text { pencatatan }\end{array}$ & $\mathrm{H}$ & $F$ & $\begin{array}{l}\text { Sistem SAP sudah } \\
\text { mendukung proses ini. } \\
\text { Pada saat penerimaan } \\
\text { barang, Bagian Logistik } \\
\text { membuat BAPB yang } \\
\text { disesuaikan dengan PO } \\
\text { perusahaan, surat jalan serta } \\
\text { keadaan dan jumlah barang } \\
\text { secara actual. }\end{array}$ & \\
\hline 8. & $\begin{array}{l}\text { Proses verifikasi pembayaran } \\
\text { (invoice verification): } \\
\text { Harus sesuai dengan barang } \\
\text { yang diterima (BAPB) }\end{array}$ & $\mathrm{H}$ & $F$ & $\begin{array}{l}\text { Proses verifikasi invoice saat } \\
\text { ini dilakukan oleh bagian } \\
\text { Purchasing. Proses verifikasi } \\
\text { melibatkan beberapa } \\
\text { dokumen seperti; BAPB, } \\
\text { BAPP (jika ada) dan scan } \\
\text { surat jalan vendor }\end{array}$ & \\
\hline 9. & $\begin{array}{l}\text { Laporan-laporan yang } \\
\text { dibutuhkan: } \\
\text { Harus memiliki format yang } \\
\text { mudah dibaca, ringkas dan } \\
\text { jelas agar dapat mempermudah } \\
\text { pengambilan keputusan }\end{array}$ & $\mathrm{H}$ & $\mathrm{P}$ & $\begin{array}{l}\text { Laporan yang dibutuhkan } \\
\text { sudah dibuat oleh team IT, } \\
\text { namun belum secara } \\
\text { maksimal digunakan. }\end{array}$ & \\
\hline
\end{tabular}

Keterangan:

$\mathrm{H}=$ high
fit




\section{PENUTUP}

Berikut simpulan ynag dapat ditarik dari hasil penelitian ini: (1) implementasi SAP telah sesuai dengan User requirement yang telah ditetapkan, tapi masih diperlukan beberapa penyesuaian bagi user dalam penggunaan sistem SAP. Mengingat sistem SAP merupakan standard best Practice bagi perusahaan; (2) penggunaan sistem SAP pada modul material management saat ini masih mengalami berbagai kendala berkaitan dengan penyesuaian kebiasaan user dan kemampuan aplikasi mendukung pekerjaan. Penggunaan sistem SAP belum optimal dilakukan mengingat masih adanya aktivitas manual yang dilakukan pada proses DPH dan PO; (3) masih adanya proses yang belum tercakup dalam pengimplementasian SAP seperti evaluasi kinerja vendor lama; (4) terjadinya keterlambatan dalam proses persetujuan PR dan PO yang berdampak pada proses selanjutnya; (5) dukungan IT terhadap perspektif pengguna masih belum mencapai target yang diharapkan sehingga kepuasan user menurun; (6) terjadi perangkapan fungsi yaitu IT yang juga memiliki otorisasi untuk menginput data vendor. Hal ini dapat mengakibatkan terjadinya penyalahgunaan wewenang; (7) tidak adanya sebuah dokumen sebagai bukti bahwa Departemen Logistik telah menyerahkan barang kepada staf departemen yang meminta pembelian.

Selanjutnya berikut sara-saran dari penulis untuk perbaikan di masa mendatang: (1) user harus diberi pelatihan secara intensif dengan proses bisnis yang menggunakan aplikasi SAP; (2) perlunya perbaikan / penyesuaian lebih lanjut dalam aplikasi SAP yang terkait dengan modul Material Management; (3) diperlukan adanya evaluasi kinerja vendor melalui sebuah fitur evaluasi vendor yang berguna untuk mengukur kinerja vendor; (4) setelah dianalisis lebih jauh kami mengusulkan di buatnya satu aplikasi reminder/notification yang berguna bagi pengguna dalam memonitor keterlambatan penyetujuan dokumen (terutama dalam hal release PR dan PO); (5) meningkatkan kinerja dari bagian help desk agar user dapat mengatasi kendala penggunaan aplikasi SAP pada saat menjalankan proses bisnis yang berhubungan dengan modul material management; (6) dibuat sebuah pemisahan tanggung jawab dengan menugaskan seseorang yang khusus bertugas dalam meng-input maupun mengubah data vendor; (7) membuat dan menggunakan sebuah dokumen yang dapat menjadi surat bukti penyerahan barang dari Bagian Logistik kepada staff departemen yang meminta pembelian.

\section{DAFTAR PUSTAKA}

Brady, J., Monk, E., Wagner, B. (2001). Concept in Enterprise Resource Planning. Canada: Thomson Learning.

Grembergen, Wim. (2000). IT balanced scorecard and IT governance. Information Systems Control Journal. Melbourne: Macmillan Education Australia.

Materials Management. (n.d). Dalam Wikipedia. Diakses dari http://en.wikipedia.org/wiki/Materials management.

O’Brien, J. A. (2000). Introduction to Information Systems (edisi 11). New York: McGraw-Hill Irwin.

Procurement. (n.d). Dalam BusinessDictionary.com. Diakses dari http://www.businessdictionary.com/definition/procurement.html.

SAP AG. (2006). SAP 01 Fundamental. Diakses dari http://www.filestube.com/s/sap01+fundamental. 